\title{
Postoperative calcium levels as a diagnostic measure for hypoparathyroidism after total thyroidectomy
}

Karen Manoela Rosa', Leandro Luongo de Matos², Cláudio Roberto Cernea², Lenine Garcia Brandão², Vergilius José Furtado de Araújo Filho²

${ }^{1}$ Faculdade de Medicina da Universidade de São Paulo (FMUSP), São Paulo, SP, Brazil ${ }^{2}$ FMUSP, Departamento de Cirurgia, Disciplina de Cirurgia de Cabeça e Pescoço, São Paulo, SP, Brazil

\begin{abstract}
Objective: The aim of the present study was to identify a fast, efficient and low-cost method to diagnose hypoparathyroidism after total thyroidectomy. Materials and methods: One hundred and forty medical records, which contained patients' clinical and laboratory data, were retrospectively analyzed. Patient parathyroid hormone values, which were obtained immediately following operation, were compared with their ionized calcium levels the morning after surgery. This comparison was used to examine the correlation between the two variables in predicting hypoparathyroidism because measuring calcium levels is low-cost and more available in the hospitals compared to measuring parathormone (PTH) levels. Results: There was a positive and statistically significant correlation between PTH and ionized calcium values (Pearson correlation coefficient, $r=0.456 ; p<0.0001$ ). The values of first postoperative day ionized calcium levels (stratified by the $1.10 \mathrm{mmol} / \mathrm{l}$ cut-off value) were tested as a diagnostic measure for hypoparathyroidism, and a PTH $<15 \mathrm{pg} / \mathrm{mL}$ obtained immediately following operation served as a reference. This analysis showed that ionized calcium levels measured on the first postoperative day had a sensitivity of $45.6 \%(95 \% \mathrm{Cl} 30.9-61.0 \%)$, a specificity of $88.9 \%(95 \% \mathrm{Cl} 80.5-94.5 \%)$ and an accuracy of 76.7\% (95\% Cl 68.7-83.5\%) as a diagnostic measure for hypoparathyroidism. Conclusion: In conclusion, we demonstrated that patients who had high ionized calcium levels on the first postoperative day also had high PTH levels immediately following operation and, therefore, they had lower rates of hypoparathyroidism. Arch Endocrinol Metab. 2015;59(5):428-33

Keywords

Thyroidectomy; hypocalcemia; hypoparathyroidism; postoperative complications; diagnosis
\end{abstract}

\section{INTRODUCTION}

$\mathrm{P}$ ost-surgery hypocalcemia is caused by an inadequate secretion of parathormone (PTH) by the parathyroids glands. Transitory hypoparathyroidism is the most frequent complication following total thyroidectomy and occurs in 16.5 to $71 \%$ (1-9) of patients. This large range in the incidence of hypoparathyroidism in the literature is explained by the heterogeneity of its diagnosis in existing studies; only clinical or a combination of clinical and laboratory diagnostic techniques have been used. Permanent hypoparathyroidism is less frequent following total thyroidectomy, with an incidence of 1.5 to $1.8 \%(3,4)$.

Patients with symptomatic hypocalcemia have cramps, tingling, paresthesia, tetanic contractions, seizures (10), muscle spasms, and QT interval prolongation on their electrocardiograms (2). Symptomatic hypocal- cemia is extremely unpleasant, it extends the hospitalization time (1-3,6-8) and it increases the treatment cost. Additionally, it is a consequence of parathyroid hypofunction. The parathyroid glands can be injured during thyroidectomy due to devascularization, mechanical damage or even accidental removal.

Hospital discharge on the first postoperative day ( $\left.1^{\text {st }} \mathrm{PO}\right)$ in thyroidectomies is reported in the literature as being safe, and it is routine in our field. The benefits of hospital discharge on the $1^{\text {st }} \mathrm{PO}$ compared to prolonged hospitalization include lower costs, less postoperative complications and better psychological outcomes (14). However, in most symptomatic patients, hypocalcemia develops on the second postoperative day $\left(2^{\text {nd }} P O\right)(8-10)$. Therefore, the lack of diagnosing hypocalcemia on the $1^{\text {st }} \mathrm{PO}$ can represent a risk to patients who may develop hypocalcemic tetanic contrac- 
tions following hospital discharge because hypocalcemia is a very harsh and potentially serious condition that requires urgent intervention.

Many researchers have studied the best way to diagnose hypocalcemia as early as possible post-thyroidectomy. Currently, the most common and effective method is measuring the PTH level immediately after the surgery through the fast intraoperative PTH assay $(1,2,5-7,9-13)$. The principle behind the fast PTH assay is that the half-life of PTH is 2 to 5 minutes (1); thus, the level of PTH 1 hour post-surgery, for example, provides a very precise indication of parathyroid function. However, the fast PTH assay is not available in the majority of the medical centers in Brazil. Another simple way to assess parathyroid function in the postoperative period is to measure the serum calcium level the morning after the surgery (1). This assay is low-cost, fast and available in every hospital. An argument against its use is that the calcium level of postthyroidectomy patients decreases quickly, which may influence its reliability in determining whether an early discharge is safe. This study aims to clarify whether calcium level is a good measure of hypoparathyroidism by evaluating the correlation between the serum calcium level on the morning after surgery and the immediate postoperative PTH level (iPO).

\section{MATERIALS AND METHODS}

This study is linked to the "Complicações de tireoidectomias. Estudo em um Serviço Universitário de Ensino" project, which was approved by the Ethics Committee for Research Project Analysis (CAPPesq No 0712/11) and is conducted by the Discipline of Head and Neck Surgery at the University of Sao Paulo School of Medicine.

We analyzed 140 consecutive medical records from adult patients who received a total thyroidectomy with or without central compartment dissection for benign and malignant thyroid diseases between June 2010 and March 2012 by the same surgical team (VJFAF).

The following data were collected: surgery date, patient's gender, indication for surgery, histopathological results, presence or absence of thyroiditis, preoperative PTH, preoperative ionized calcium, preoperative 25-hydroxy vitamin $\mathrm{D}$, immediate postoperative $\mathrm{PTH}$, ionized calcium on the first postoperative day $\left(\mathrm{I}^{\text {st }} \mathrm{PO}\right)$, hypoparathyroidism (based on Chvostek's and Trousseau's signs, cramps, and tetanic contractions) on the first postoperative day, PTH between the $2^{\text {nd }}$ and $6^{\text {th }}$ months after the surgery ("late" PTH), and ionized calcium between the $2^{\text {nd }}$ and $6^{\text {th }}$ months after the surgery ("late" CaI).

The following assays were employed in each laboratory investigation: chemiluminescence for detecting PTH (referential values: 10 - $65 \mathrm{pg} / \mathrm{mL}$ ); an ion-selective electrode for detecting ionized calcium (reference values: $1.11-1.40 \mathrm{mmol} / \mathrm{l}$ ); and high performance liquid chromatography for detecting 25 -hydroxy vita$\min \mathrm{D}(25 \mathrm{OHD}$; reference values: $30-60 \mathrm{ng} / \mathrm{mL})$.

\section{Statistical analysis}

The quantitative variables that had a parametric distribution are presented as a mean and standard deviation. The qualitative variables are presented as absolute and relative frequencies. The variable distributions were defined as parametric by the Kolmogorov-Smirnov Test. The relationship between qualitative variables was analyzed by comparing their frequencies using the ChiSquare test or the Fisher's Exact test. The Pearson correlation coefficient was used to analyze the correlation between two continuous variables. An ROC (Receiver Operating Characteristic) curve was used to validate the diagnostic tests, and the test specificity and sensitivity, the area under the ROC curve, the positive and negative predictive values, and the 95\% Confidence Intervals (95\% CI) were also calculated. The statistical software SPSS ${ }^{\circledR}$ version 17.0 (SPSS ${ }^{\circledR}$ Inc.; Illinois, USA) was used for all analyses, and the statistical significance was set at $\mathrm{p} \leq 0.05$.

The cut-off values (or stratification) were based on the following laboratory reference values: ionized calcium (CaI) of $1.10 \mathrm{mmol} / \mathrm{l}$ (values less than 1.10 $\mathrm{mmol} / \mathrm{L}$ were considered low and values greater than or equal to $1.10 \mathrm{mmol} / \mathrm{l}$ were considered normal); PTH of $15 \mathrm{pg} / \mathrm{mL}$ (values less than $15 \mathrm{pg} / \mathrm{mL}$ were considered low and values greater than or equal to 15 $\mathrm{pg} / \mathrm{mL}$ were considered normal).

\section{RESULTS}

Of the one hundred and forty patients whose records were analyzed, the majority were female and between 40 and 59 years of age and had an indication of surgery due to malignant thyroid disease, predominantly papillary carcinoma. A detailed profile of the patient sample can be found in table 1 . 
Table 1. Characteristics of the sample $(N=140)$

\begin{tabular}{|c|c|}
\hline Age $^{*}$ & $46.6 \pm 12.4$ years \\
\hline \multicolumn{2}{|l|}{ Gender } \\
\hline Male & 40 (28.6\%) \\
\hline Female & $100(71.4 \%)$ \\
\hline \multicolumn{2}{|l|}{ Age at the time of surgery } \\
\hline 10-19 years & $2(1.4 \%)$ \\
\hline 20-29 years & $7(5.0 \%)$ \\
\hline 20-39 years & 38 (27.1\%) \\
\hline 40-49 years & 39 (27.9\%) \\
\hline $50-59$ years & $31(22.1 \%)$ \\
\hline $60-69$ years & $20(14.3 \%)$ \\
\hline $70-79$ years & $3(2.1 \%)$ \\
\hline Total & 140 \\
\hline \multicolumn{2}{|l|}{ Indication of surgery } \\
\hline Benign disease & $58(42.0 \%)$ \\
\hline Malignant disease & $80(58.0 \%)$ \\
\hline Total & 138 \\
\hline \multicolumn{2}{|l|}{ Graves' disease } \\
\hline Presence & $4(2.9 \%)$ \\
\hline \multicolumn{2}{|l|}{ Thyroiditis } \\
\hline Presence & $30(21.7 \%)$ \\
\hline \multicolumn{2}{|l|}{ Cancer histologic type } \\
\hline Follicular carcinoma & $2(2.4 \%)$ \\
\hline Papillary carcinoma & 80 (96.4\%) \\
\hline Medullary carcinoma & $1(1.2 \%)$ \\
\hline \multicolumn{2}{|c|}{ Hypoparathyroidism symptoms } \\
\hline Absence & $123(95.3 \%)$ \\
\hline Presence & $6(4.7 \%)$ \\
\hline \multicolumn{2}{|l|}{ Intraoperative PTH } \\
\hline Normal & $90(66.2 \%)$ \\
\hline Less than $15 \mathrm{pg} / \mathrm{mL}$ & $46(33.8 \%)$ \\
\hline
\end{tabular}

* Mean \pm standard deviation.-

PTH, total serum calcium, ionized calcium and 25-hydroxy vitamin D levels were measured at different time points and are displayed in table 2 .

Table 2. Quantitative data

\begin{tabular}{|c|c|}
\hline Variable & Result* \\
\hline Preoperative PTH $(n=122)$ & $44.50 \pm 20.2(7.0-146.0) \mathrm{pg} / \mathrm{mL}$ \\
\hline Preoperative ionized calcium $(n=130)$ & $1.2 \pm 0,1(0.8-1.4) \mathrm{mmol} / \mathrm{l}$ \\
\hline Preoperative 25 -hydroxy vitamin $D(n=110)$ & $26.7 \pm 10.1(8.5-63) \mathrm{ng} / \mathrm{mL}$ \\
\hline Immediate postoperative PTH $(n=136)$ & $30.5 \pm 26.4(2.0-144) \mathrm{pg} / \mathrm{mL}$ \\
\hline First postoperative ionized calcium $(n=140)$ & $1.13 \pm 0.0(0.9-1.2) \mathrm{mmol} / \mathrm{l}$ \\
\hline Late PTH $(n=81)$ & $39.0 \pm 20.3(8-144) \mathrm{pg} / \mathrm{mL}$ \\
\hline Late ionized calcium $(n=107)$ & $1.2 \pm 0.1(0.7-1.8) \mathrm{mmol} / \mathrm{l}$ \\
\hline
\end{tabular}

Patients' ionized calcium levels on the $\mathrm{l}^{\text {st }}$ postoperative day ( $\left.1^{\text {st }} \mathrm{PO} \mathrm{CaI}\right)$ were compared to their clinical and histopathological results, and there were no statistically significance differences. The complete results are presented in table 3 .

Table 3. Ionized calcium on the first postoperative day ( $1^{\text {st }}$ PO Cal) compared with the clinical variables

\begin{tabular}{|c|c|c|c|}
\hline Variables & $\begin{array}{l}1^{\text {st }} \mathrm{PO} \mathrm{Cal}< \\
1.10 \mathrm{mmol} / \mathrm{l}\end{array}$ & $\begin{array}{l}1^{\text {st }} \mathrm{PO} \mathrm{Cal} \geq \\
1.10 \mathrm{mmol} / \mathrm{l}\end{array}$ & p \\
\hline $\begin{array}{l}\text { Hypoparathyroidism } \\
\text { symptoms }\end{array}$ & $3 / 43(6.9 \%)$ & 3/86 (3.4\%) & $0.400 \dagger$ \\
\hline \multicolumn{4}{|l|}{ Gender } \\
\hline Male & $9 / 40(22.5 \%)$ & $31 / 40(77.5 \%)$ & \multirow{2}{*}{$0.099^{*}$} \\
\hline Female & $37 / 100(37.0 \%)$ & $63 / 100(63.0 \%)$ & \\
\hline \multicolumn{4}{|c|}{ Histopathological study } \\
\hline Malignant & $25 / 80(31.2 \%)$ & $55 / 80(68.7 \%)$ & \multirow[t]{2}{*}{$0.451^{*}$} \\
\hline Benign & 21/58 (36.2\%) & 37/58 (63.8\%) & \\
\hline Graves' disease & $2 / 46(4.3 \%)$ & 2/93 (2.1\%) & $0.599+$ \\
\hline Thyroiditis presence & $13 / 46(28.2 \%)$ & 17/92 (18.4\%) & $0.181^{*}$ \\
\hline
\end{tabular}

${ }^{*}$ Chi-square test; $\uparrow$ Fisher's exact test.

When the ionized calcium levels were compared to the immediate postoperative (iPO) PTH levels, there was a positive and statistically significant correlation between the values (Pearson correlation coefficient, $\mathrm{r}=0.456 ; \mathrm{p}<0.0001)$. Thus, the stratified ionized calcium values were compared to the stratified PTH values, to evaluate if $1^{\text {st }} \mathrm{PO} \mathrm{CaI}$ level is a predictor of hypoparathyroidism, like PTH level, and a significant relationship was found (Chi-square test, $\mathrm{p}<0.0001$ ). These results are described in table 4 . This demonstrates that the patients who had high levels of ionized calcium on the first postoperative day also had high levels of immediate postoperative PTH values, and therefore, they had lower rates of hypoparathyroidism.

Table 4. Correlation between $1^{\text {st }} \mathrm{PO}$ Cal and PTH in the IPO

\begin{tabular}{lccc}
\hline & $\mathbf{C a}<\mathbf{1 . 1 0} \mathbf{~ m m o l} / \mathbf{I}$ & $\mathbf{C a} \geq \mathbf{1 . 1 0} \mathbf{~ m m o l} / \mathbf{l}$ & $\mathbf{p}$ \\
\hline PTH & & & \\
$<15$ & $25 / 43(58.1 \%)$ & $21 / 93(22.6 \%)$ & $<0.0001$ \\
$\geq 15$ & $18 / 43(41.9 \%)$ & $72 / 93(77.4 \%)$ & (Chi-square test) \\
\hline
\end{tabular}

The $1^{\text {st }}$ PO CaI values were stratified according to the cut-off point of $1.10 \mathrm{mmol} / \mathrm{l}$ and plotted on a ROC curve to analyze whether this threshold is an adequate cut-off point for diagnosing hypoparathyroidism. The results show that the cut-off point had a sensitivity of $50 \%$ (95\% CI $11.8-88.2 \%)$, specificity of $76.4 \%$ (95\% CI $67.9-83.6 \%)$, and positive and negative predictive values of $9.4 \%(95 \%$ CI $1.9-25.4 \%)$ and $96.9 \%(95 \%$ 
CI 91.2-99.4\%), respectively, with an accuracy of $66.3 \%$ (95\% CI 57.5-74.4\%).

In a second analysis, the $1^{\text {st }} \mathrm{PO} \mathrm{CaI}$ values were stratified according to the cut-off point of $1.10 \mathrm{mmol} / \mathrm{l}$ and plotted on a ROC curve with immediate postoperative $\mathrm{PTH}<15 \mathrm{pg} / \mathrm{mL}$ serving as a reference. In this case, the cut-off point had a sensitivity of $45.6 \%$ (95\% CI 30.9-61.0\%), a specificity of $88.9 \%$ (95\% CI 80.5$94.5 \%)$, and positive and negative predictive values of 67.7\% (95\% CI 48.6-83.3\%) and 76.2\% (95\% CI 66.8$84.0 \%)$, respectively, with an accuracy of $76.7 \%(95 \%$ CI 68.7-83.5\%). These values were also compared with symptoms of hypocalcemia as a reference with inferior results, demonstrating the subjectivity of this analysis (accuracy of $66.3 \%$ ). The results of the ROC curve analyses are described in figure 1 .
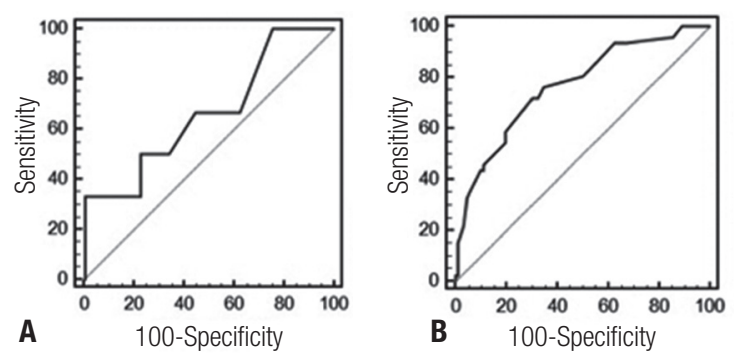

Figure 1. ROC curves demonstrating (A) the accuracy of $1^{\text {st }} \mathrm{PO}$ Cal level as a predictor of hypoparathyroidism (area under the ROC curve, 66.3\%) with symptoms of hypocalcemia as a reference, and (B) the accuracy of $1^{\text {st }}$ PO Cal level as a predictor of hypoparathyroidism with PTH $<15 \mathrm{pg} / \mathrm{mL}$ as a reference (area under the ROC curve, $76.7 \%$ ).

\section{DISCUSSION}

Hypoparathyroidism is the most common complication of total thyroidectomies, and in addition to causing extremely unpleasant symptoms, it requires longer hospitalization and results in higher costs for patients and the health system $(15,16)$.

Not all hypocalcemic patients are symptomatic, but among those who are, the condition manifests after the second postoperative day. Because total thyroidectomy patients tend to be discharged early, it is important to find a safe and economic method that can predict hypoparathyroidism and allow patients who do not develop hypoparathyroidism or who develop very mild hypoparathyroidism to be discharged early, perhaps with a moderate oral calcium supplement. The patients who develop severe disease should be hospitalized for the longest time to receive intravenous and oral replacement of calcium and vitamin D. This would ensure that tetanic contractions occurring after discharge, which is often very dramatic and potentially serious, are prevented.

Many surgeons routinely supplement calcium and vitamin $\mathrm{D}$ in all patients who have total thyroidectomies $(17,18)$. Although this practice is effective in reducing the number of symptomatic patients, it can be inconvenient because the treatment is expensive and poorly tolerated. In addition, it is not $100 \%$ effective, and patients with severe hypocalcemia may experience tetanic contractions despite treatment. Lastly, many patients are unnecessarily medicated (1). Cahill and cols. (19) did not recommend routine supplementation because they found that the administration of calcium and/or vitamin $\mathrm{D}$ in normal patients could result in the following: (1) inhibit the functioning of the parathyroid glands; (2) overestimate the amount of patients who need calcium and magnesium replacement; and ( 3 ) hide the true incidence of hypoparathyroidism, which may prevent surgeons from making changes to optimize treatment.

Another option is only treating symptomatic patients (2), but this would require a longer hospitalization time, which is very difficult.

The best alternative is a reliable way to predict which patients will develop hypocalcemia. This would allow for only those who truly need treatment to be treated and for the intensity of the replacement therapy to be individualized in each case. The "gold standard" for diagnosing hypoparathyroidism is the fast PTH assay, which measures iPO PTH, and it is the most employed method (20-23). However, it is not yet available in most medical centers in Brazil.

In this study, we evaluated the blood ionized calcium level on the morning after total thyroidectomy as an alternative predictor of hypoparathyroidism to the iPO PTH level. We found that there is a positive correlation between iPO PTH levels and calcium levels on the $\mathrm{I}^{\text {st }} \mathrm{PO}$ day after thyroidectomy. It is important to note that two patients had high PTH (146 pg/mL) or ionized calcium $(1.40 \mathrm{mmol} / \mathrm{l})$ levels and were investigated for primary hyperparathyroidism before surgery. Hyperfunctional glands were not identified preoperatively, and enlargement of the glands was not noted during their thyroidectomies.

PTH has a very short half-life, which allows for the quick identification of intraoperative parathyroid lesions (24). Therefore, PTH remains the best way to predict early hypoparathyroidism. However, the correlation between iPO PTH levels and calcium levels on 
the $\mathrm{I}^{\text {st }} \mathrm{PO}$ day found in our study is relevant in situations where the fast PTH assay is unavailable. Thus, serum calcium level is a good diagnostic measure of hypoparathyroidism after total thyroidectomy because it is available in most centers and has a lower cost.

Pia Lindblom and cols. (5) also compared serum calcium levels on the morning after a total thyroidectomy with iPO PTH levels and found that calcium level is not as effective as iPO PTH level in predicting hypocalcemia. They attribute this difference to the hemodilution of serum calcium during surgery. In fact, their data confirm that the accuracy of iPO PTH in predicting symptomatic and asymptomatic hypocalcemia is not very different from that of low concentrated calcium on the first postoperative morning.

Nahas and cols. (16) recommend using an algorithm that incorporates serum calcium level after thyroidectomy to identify patients who are at low risk of developing hypocalcemia and, consequently, can be discharged 24 hours after surgery. This algorithm shows that an increase in serum calcium between 6 and 12 hours after surgery is a reliable predictor of patients who will not develop significant hypocalcemia.

Cahill and cols. (19) suggest that hemodilution during surgery and the release of calcitonin are causes of transient hypocalcemia, which does not progress to hypoparathyroidism; therefore, the level of serum calcium after thyroidectomy is not a reliable way of predicting the onset of hypoparathyroidism. However, our findings contradict this hypothesis.

In our study, we also analyzed ionized calcium level on the first postoperative day by gender, the clinical presentation of hypoparathyroidism, the histophatological results of surgery, the presence of Graves' disease and the presence of thyroiditis. However, we did not find any associations between these conditions and hypoparathyroidism.

In accordance with our findings, Lam and Kerr (22) found that a greater proportion of the women in their study were affected by thyroid disease, but that there was no association between patient sex and hypoparathyroidism. They also found that hypoparathyroidism was not correlated with age or indication of surgery (i.e., malignancies, Graves' disease, goiter, and familial endocrine disease).

Toniato and cols. (15) found a strong association between hypoparathyroidism and Graves' disease and suggest that this relationship is due to the fact the location and preservation of the parathyroid glands in patients with Graves' disease is more difficult. One possible explanation for why we did not find a similar association it that there were only a few Graves' disease patients in our sample.

Del Rio and cols. (25) found a positive and statistically significant correlation between developing hypocalcemia and being treated for malignant thyroid diseases. Our findings do not support this hypothesis, and one possible explanation is that the thyroidectomies in our sample treated benign and malignant diseases with a very similar technique, and most of these were small tumors.

\section{CONCLUSION}

Our study shows that measuring serum ionized calcium levels on the first postoperative morning is not more effective than the fast PTH assay. However, when the PTH test is not available, the level of serum calcium is a very good indicator of parathyroid function. In our study, patients with an ionized calcium level above the cut-off point of $1.1 \mathrm{mmol} / \mathrm{L}$ had a normal PTH level in $77.4 \%$ of the cases; patients with an ionized calcium level below $1.1 \mathrm{mmol} / \mathrm{L}$ had a PTH level that was below the lower limit in $58.1 \%$ of the cases.

Acknowledgement: we thank the Fundação de Amparo à Pesquisa do Estado de São Paulo (Fapesp) for the Scientific Initiation Scholarship that they provided to perform this study.

Disclosure: no potential conflict of interest relevant to this article was reported.

\section{REFERENCES}

1. Cavicchi O, Piccin O, Caliceti U, Fernandez IJ, Bordonaro C, Saggese D, et al. Accuracy of PTH assay and corrected calcium in early prediction of hypoparathyroidism after thyroid surgery. Otolaryngol Head Neck Surg. 2008;138(5):594-600.

2. Gentileschi P, Gacek IA, Manzelli A, Coscarella G, Sileri P, Lirosi $F$, et al. Early (1 hour) post-operative parathyroid hormone (PTH) measurement predicts hypocalcaemia after thyroidectomy: a prospective case-control single-institution study. Chir Ital. 2008;60(4):519-28.

3. Lewandowicz M, Kuzdak K, Pasieka Z. Intraoperative parathyroid hormone measurement in thyroidectomized patients: preliminary report. Endocr Regul. 2007;41(1):29-34.

4. Hermann M, Ott J, Promberger R, Kober F, Karik M, Freissmuth M. Kinetics of serum parathyroid hormone during and after thyroid surgery. Br J Surg. 2008;95(12):1480-7.

5. Lindblom P, Westerdahl J, Bergenfelz A. Low parathyroid hormone levels after thyroid surgery: a feasible predictor of hypocalcemia. Surgery. 2002;131(5):515-20.

6. Zewska MPM, Kobiela J, Stefaniak T, Lachinski AJ, Sledzinski Z. Postoperative PTH measurement as a predictor of hypocalcaemia after thyroidectomy. Polski Przegl Chirurgiczny. 2010;82(1):24-8. 
7. Soon PS, Magarey CJ, Campbell P, Jalaludin B. Serum intact parathyroid hormone as a predictor of hypocalcaemia after total thyroidectomy. ANZ J Surg. 2005;75(11):977-80.

8. Tredici P, Grosso E, Gibelli B, Massaro MA, Arrigoni C, Tradati N. Identification of patients at high risk for hypocalcemia after total thyroidectomy. Acta Otorhinolaryngol Ital. 2011;31(3):144-8.

9. Pareed KD, Ananthprabhu K, Moosabba MS. Intact PTH measurement 1 hour after total thyroidectomy as a predictor for patients at risk for developing symptomatic hypocalcaemia. Int J Biomed Adv Res. 2015;6(01):11-4.

10. Grodski S, Farrell S. Early postoperative PTH levels as a predictor of hypocalcaemia and facilitating safe early discharge after total thyroidectomy. Asian J Surg. 2007;30(3):178-82.

11. Wiseman JE, Mossanen M, Ituarte PH, Bath JM, Yeh MW. An algorithm informed by the parathyroid hormone level reduces hypocalcemic complications of thyroidectomy. World J Surg. 2010;34(3):532-7.

12. Quiros RM, Pesce CE, Wilhelm SM, Djuricin G, Prinz RA. Intraoperative parathyroid hormone levels in thyroid surgery are predictive of postoperative hypoparathyroidism and need for vitamin D supplementation. Am J Surg. 2005;189(3):306-9.

13. AlQahtani A, Parsyan A, Payne R, Tabah R. Parathyroid hormone levels 1 hour after thyroidectomy: an early predictor of postoperative hypocalcemia. Can J Surg. 2014;57(4):237-40.

14. Dedivitis RA, Pfuetzenreiter EG Jr, Castro MA, Denardin OV. Analysis of safety of short-stay thyroid surgery. Acta Otorhinolaryngol Ital. 2009;29(6):326-30.

15. Toniato A, Boschin IM, Piotto A, Pelizzo M, Sartori P. Thyroidectomy and parathyroid hormone: tracing hypocalcemia-prone patients. Am J Surg. 2008;196(2):285-8.

16. Nahas ZS, Farrag TY, Lin FR, Belin RM, Tufano RP. A safe and costeffective short hospital stay protocol to identify patients at low risk for the development of significant hypocalcemia after total thyroidectomy. Laryngoscope. 2006;116(6):906-10.

17. Tartaglia F, Giuliani A, Sgueglia M, Biancari F, JuvonenT, Campana FP. Randomized study on oral administration of calcitriol to prevent symptomatic hypocalcemia after total thyroidectomy. Am J Surg. 2005;190(3):424-9.

18. El-Shinawi M, El-Anwar A, Nada M, YoussefT, Fakhry E, Raslan S, El-Gohry $\mathrm{H}$. Oral calcium and vitamin D supplementation after total thyroidectomy. Thyroid Res Pract. 2015;11(3):98-102.

19. Cahill RA, Harty R, Cotter S, Watson RG. Parathormone response to thyroid surgery. Am J Surg. 2006;191(4):453-9.

20. Grodski S, Farrell S. Early postoperative PTH levels as a predictor of hypocalcaemia and facilitating safe early discharge after total thyroidectomy. Asian J Surg. 2007;30(3):178-82.

21. Noordzij JP, Lee SL, Bernet VJ, Payne RJ, Cohen SM, McLeod IK, et al. Early prediction of hypocalcemia after thyroidectomy using parathyroid hormone: an analysis of pooled individual patient data from nine observational studies. J Am Coll Surg. 2007;205(6):748-54

22. Lam A, Kerr PD. Parathyroid hormone: an early predictor of postthyroidectomy hypocalcemia. Laryngoscope. 2003;113(12):2196200.

23. Del Rio L, Castro A, Bernáldez R, Del Palacio A, Giráldez CV, Lecumberri $B$, et al. Parathyroid hormone as a predictor of post-thyroidectomy hypocalcemia. Acta Otorrinolaringol Esp. $2011 ; 62(4): 265-73$.

24. Fezer GF, Delfes RA, Gama RR. Parathyroid hormone level after total thyroidectomy as a predictor of symptomatic hypocalcemia prospective Study. Rev Bras Cir Cabeça Pescoço. 2012;41(2):58-64.

25. Del Rio P, Arcuri MF, Ferreri G, Sommaruga L, Sianesi M. The utility of serum PTH assessment 24 hours after total thyroidectomy. Otolaryngol Head Neck Surg. 2005;132(4):584-6. 